\title{
SUITABILITY OF COMMERCIALLY AVAILABLE SANDCRETE BLOCKS IN ABUJA MUNICIPAL AREA FOR USE AS STREET SIDE DRAIN WALLING MATERIALS
}

\section{MANASSEH JOEL AND ADIE GABRIEL UTYANKPAN}

(Received 14 July 2015; Revision Accepted 16 October 2015)

\begin{abstract}
Commercially available sandcrete blocks produced in Abuja municipal area of the Federal Capital Territory (FCT) Nigeria was investigated, to ascertain their suitability for use as side drain walling material. Block samples produced using a standard mix (SM) ratio of cement: sand of 1: 6 and block samples obtained from five different commercial sandcrete block producing factories, labelled A, B, C, $\mathrm{D}$, and $\mathrm{E}$ were obtained and subjected to compressive and water absorption tests. Blocks produced with the standard mix ratio, and those obtained from factory $A, B, C, D$ and $E$ have 28 day average compressive strength values of $0.65,0.56,0.56,0.980 .94$ and $2.89 \mathrm{~N} / \mathrm{mm}^{2}$ respectively, and water absorption values of $8.6,9.4,9.5,8.1,7.8$ and $5.1 \%$ respectively. Based on results of test commercially available sandcrete blocks in Abuja Municipal area are and blocks produced with the standard mix of (1:6) are not suitable for use as side drain walling materials. Suitability of commercially available sandcrete blocks for use as side drain walling material can be enhanced if a mix proportion richer than the standard mix is used in block production.
\end{abstract}

KEYWORDS: Sandcrete blocks, Side drain, Compressive Strength, Water absorption.

\section{INTRODUCTION}

Longitudinal or side drains are very important components of highway. During rains, part of the rain water flows from the carriage way and adjoining land into the longitudinal or side drains. The water from the side drain is disposed off at the nearest stream, valley or water course. The drain is very significant to having a good and durable pavement, as increase in moisture content of any component of the pavement, according to Khanna, and Justo (2001) can result in strength reduction of pavement layer, formation of waves and corrugations in flexible pavements and mud pumping in rigid pavement. Other road failure associated with poor or non availability of side drain as presented by Sharma (2012) are softening of the ground above and below the road pavement, where it goes along the high ground.

A typical side drain is made up of the floor and walls. The floor is normally made of reinforced concrete, while the wall can be made up of reinforced concrete, crushed stones, or sandcrete blocks. Sandcrete blocks are commonly used as side drain walling materials where economics is not in favour of reinforced concrete walls. Sandcrete blocks with its voids filled with weak concrete mix are normally used as alternative side drain walling materials on street pavement.

British Standard 6073 (1981) part 1 defines a block as a masonry unit of large size in all dimensions than specified for bricks but no dimension should exceed $650 \mathrm{~mm}$ nor should the height exceed either its length or six times its

Manasseh Joel, Civil Engineering Department, University of Agriculture Makurdi, PMB, 2373 Makurdi Benue State, Nigeria.

Adie Gabriel Utyankpan, Civil Engineering Department, University of Agriculture Makurdi, PMB, 2373 Makurdi Benue State, Nigeria. 
thickness. Seeley (1993) defined sandcrete blocks as walling materials that are made of coarse natural sand or crushed rock dust mixed in proportion with cement and water and is moderately compacted into shapes. It broadly has porous rough surface ans ashy or grayish in colour. Sandcrete hollow block is a block having one or more large holes or cavities which pass through the block and the solid material is between $50 \%$ and $75 \%$ of the total volume of the block.

Sandcrete blocks are made in different sizes and shape, but the most common type is rectangular in shape either hollow or solid. The depth and breadth of $225 \mathrm{~mm}$, and are used as load bearing wall. While blocks with dimensions of $450 \mathrm{~mm}$ in length and depth of $225 \mathrm{~mm}$ and breadth of $150 \mathrm{~mm}$ are used for partitioning. The major materials used in sandcrete block production according to Sadiku and Aguwa (2013) are cement, sand and water, when the materials are mixed together in a determined proportion. Cement normally serves as the bonding agent, while sand particles provide the skeleton or particles to be bonded. The bonding action is due to the hydration of cement.

Boeck, et al (2000) reported low average compressive strength value of $1.21 \mathrm{~N} / \mathrm{mm}^{2}$ and $0.73 \mathrm{~N} / \mathrm{mm}^{2}$ in dry and wet state respectively, when commercially available sandcrete blocks obtained from block-making factories within the Federal Capital territory, Abuja Nigeria were subjected to test. Abdullahi (2005) reported low compressive strength values far below the standard requirements for the construction of houses when commercially available sandcrete blocks in Boss and Shiroro area of Minna, Niger state, Nigeria was studied. Similar observation was reported by Banuso and Ejeh (2008) when the quality of commercial available sandcrete blocks in Kaduna state, Nigeria was assessed.

The suitability of sandcrete blocks for use as walling materials is normally assessed using strength and water absorption indices. The strength is normally determined using compressive strength test, while durability is assessed using water absorption test. The compressive strength of sandcrete block according to Banuso and Ejeh (2008) depends on variables that affect it during production. These include the amount of cement, fine aggregate, water, degree of compaction, the curing conditions, the age of the cement and the type of weather. The Nigerian industrial standard (2004) specifies that the lowest compressive strength of individual load bearing blocks shall not be less than $2.5 \mathrm{~N} / \mathrm{mm}^{2}$ and average compressive strength of five blocks shall not be less than $3.45 \mathrm{~N} / \mathrm{mm}^{2}$. The compressive strength of sandcrete materials increases with increase cement content Vallenger (1971). However, strength alone is not to be taken as an indication of durability BS 3921 (1965). Water absorption and porosity of blocks is also essential, although in most cases it is very difficult to have bricks satisfying compressive strength requirements being deficient in water absorption values. Standard organization of Nigeria, a regulatory authority responsible for quality control of sandcrete blocks production in Nigeria specified a compressive strength value range of $2.5 \mathrm{~N} / \mathrm{mm}^{2}$ to $3.45 \mathrm{~N} / \mathrm{mm},{ }^{2}$ for a load bearing wall and the value range of $1.8 \mathrm{~N} / \mathrm{mm}^{2}$ and $2.5 \mathrm{~N} / \mathrm{mm}^{2}$ for nonload bearing walls.

The volume of liquid absorbed by a porous medium is an indication of its pore volume and it is a good approximate measure of its porosity. Hence, porosity $u$ is obtained with the relationship presented in equation (1)

$$
\begin{aligned}
& \mathrm{u}=\frac{v_{f}}{V} X 100 \% \\
& \mathrm{u}=\text { porosity of the material }(\%) \\
& v_{\mathrm{f}}=\text { volume of water absorbed }\left(\mathrm{m}^{3}\right) \\
& \mathrm{v}=\text { volume of material sample }\left(\mathrm{m}^{3}\right)
\end{aligned}
$$

Porosity is the relationship between water absorbed and volume of a material. Water absorption is a measure of the relationship between the weight of water absorbed and weight of a material.

Water absorption $=\frac{\text { weight of moisture absorbed } X 100}{\text { Weight of Dry material }}(2)$

Although Oyekan and Kamiyo (2011) recommended sorptivity test. Sorptivity is a measure of the capacity of a porous medium to absorb liquid by capillary. The absorption of water under capillary action is directly proportional to the square-root of time (Hall, 1989).

$$
\begin{aligned}
& A^{\prime \prime}=S \sqrt{t} \\
& A^{\prime \prime}=\text { cumulative infiltration } \\
& S=\text { sorptivity }\left(\mathrm{m} / \mathrm{s}^{1 / 2}\right) \\
& \mathrm{t}=\text { time }(\mathrm{min})
\end{aligned}
$$

According to Oyekan and Kamiyo (2011) blocks to be used in the construction of channels for drainage is expected to have low sorptivity 
value. Porosity, water absorption and soprtivity of a sancrete block is all a function of the pores in the sandcrete blocks. For the purpose of this research, water absorption test will be used in the assessment of the pores in the sandcrete blocks. This is because of the simplicity of the test. Maximum water absorption value of $7 \%$ specified by BS 2028 (1970) will also be adopted for the study.

Research records on the quality of sandcrete blocks used in buildings and construction of walls abound, but little has been done on the suitability of sandcrete blocks for use as side drain walling materials, hence the need for such a study. The aim of this study is to ascertain the compressive and water absorption values of commercially available blocks, in order to assess their suitability for use as side drain walling materials.

\section{MATERIALS AND METHODS}

The materials used in the production of sandcrete blocks in the study area are cement, sand and water. Interaction with the block moulding factories revealed that Burham protland cement of grade 42.5 was used for the production of sandcrete blocks. Hence its usage in the production of blocks using standard mix proportion of 1: 6 (1 part of cement: 6 Part of sand by volume).

Sand: The fine aggregate used in the production of sandcrete blocks in the area was sand obtained from Masaka river, in Nassarawa state. The same sand was used in the production of standard blocks.

Water: Water used for the production of sandcrete blocks within the research area was fresh water from the river. The same water sample was used in the production of standard sandcrete blocks. The water was observed to be clean and free from impurities.

\section{METHODS}

Two approaches were adopted in the study, namely personal observation and laboratory tests. The former was carried out to determine the materials used in block production, the mix ratio of the blocks produced, the batching method used, the quantity of water added to each mix, the curing method and duration.

A total of 66 commercial block moulding factories were indentified in Abuja Municipal area, of the Federal Capital territory (FCT). Out of this number, 39 of the factories moulded their blocks with stone dust, while the remaining 27 factories use river sand as the main aggregate for block production. The use of river sand was considered in this study because it was more economical and low strength was reported to be associated with their usage in sandcrete block production. Elinwa and Chido-Amajunyi (1991) reported higher strength with the use of crushed granite fine when compared with the singular use of river sand; the same observation was reported by Agbede and Joel (2004). Five (5) well known block moulding factories using different mix ratios were randomly selected for the study. The selected factories were labelled as A, B, C, D, and $E$ respectively. The size of hollow block selected for the study is $450 \mathrm{~mm} \times 225 \mathrm{~mm} \times 225$ $\mathrm{mm}$. Thirty five (35) units of blocks were produced using the standard mix of $1: 6$ by volume using the same sand sample and the one of the block moulding machine used in one of the five block moulding factories. The same numbers of blocks were sampled from each of the five (5) selected block moulding factories. Particle size distribution of the river sand used in the production of the blocks was determined using sieve analysis test. Mixing of cement and sand for the production of sandcrete blocks was done manually, using sand and cement mixed together intimately before water was added to the mix. Batching was by volume which is the most common method used for block production. The predetermine water to cement ratio was used as a guide in the addition of water. The paste was then placed in a mould fitted to a block moulding machine. It was then rammed into the machine moulds, compacted through vibration and smoothed off with a steel face tool. The fresh block was removal from the machine moulds, and left on pallets under cover in separate rows, for curing. The fresh blocks were allowed to cure for 24 hours before the spraying of blocks with water in the morning and evening for 28 days. Blocks were removed for testing after 7,14 , and 28 days. 10 blocks each were used for compressive strength test.

The blocks were sand witched between two metal plates, and well positioned in the compressive testing machine of an ELE $1500 \mathrm{kN}$ capacity compressive testing machine, before it was subjected to load. The load was gradually applied without shock until the block failed. The maximum load sustained by the blocks before failure was divided by the effective area of the 
blocks and taken as the compressive strength value of the block. The same procedure was adopted for all the blocks tested at the different curing days.

Five (5) blocks were subjected to water absorption test after 28 days of curing. Water absorption test was performed by immersing the blocks completely inside water, in a curing tank. And the difference in weight between the blocks before and after immersion divided by the weight before immersion multiplied by one hundred percent gave the water absorption value of the blocks, the average value of five blocks subjected to the test was used as the water absorption values of blocks from a given block moulding factory.

\section{RESULTS AND DISCUSSION}

\section{Personal observation}

I. Materials used: it was discovered that all five factories selected for the study used river sand obtained from Masaka, river for block production. The sand was uniformly graded Medium grain sand sample in accordance with BS 882 (1992). The specific gravity value of the sand sample was 2.6 and within the limit for natural aggregate as reported by Neville, (1995).

II. The mix ratio (of cement: sand by volume) used in the production of blocks in the five block factories are 1:10, 1:11, $1: 12,1: 13$ and $1: 14$ for block industries $A, B, C, D$, and $E$ respectively. The mix ratio and $w / c$ ratio used in the block factories are presented in Table 1.

III. Batching method: it was observed that the batching method adopted was the same at the five factories. Batching was by volume.

IV. Addition of water: The water to cement ratio used in the different factories are tabulated in Table 1.

Table 1: Summary of mix ratio and water/cement ratio used in the different block factories

\begin{tabular}{|l|l|l|l|l|l|l|}
\hline Block Factory & A & B & C & D & E & SM \\
\hline Mix Ratio & $1: 12$ & $1: 13$ & $1: 14$ & $1: 10$ & $1: 11$ & $1: 6$ \\
\hline W/C & 0.49 & 0.50 & 0.52 & 0.47 & 0.48 & 0.45 \\
\hline \multicolumn{7}{|c|}{ SM Standard Mix Ratio of (1:6). }
\end{tabular}

The particle size distribution curve of the sand sample obtained from Masaka river used in block production is presented in Figure 1. Sieve analysis result shows that the sand sample can be classified as Medium grain sand in accordance with BS 882

(1992). 


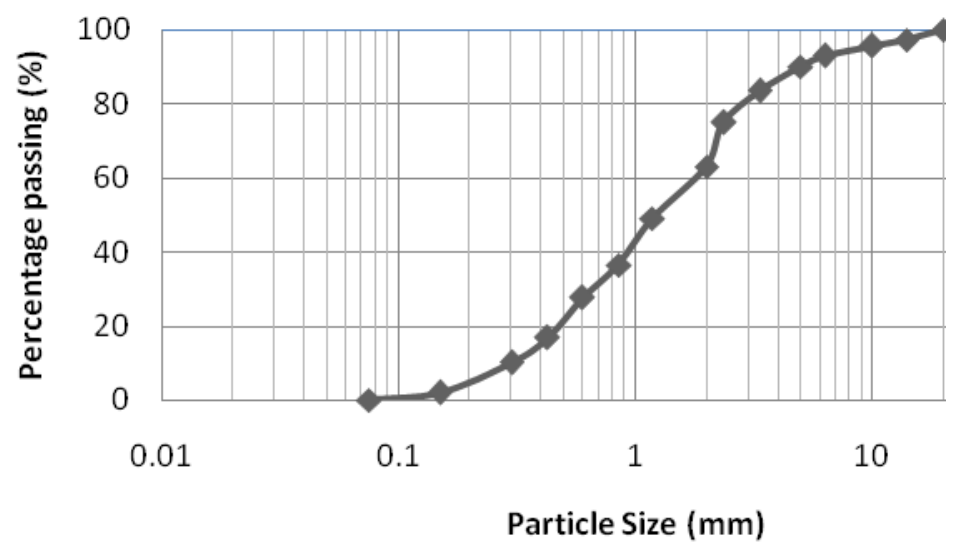

Figure 1: Particle size distribution curve of sand obtained from River Masaka

\section{COMPRESSIVE STRENGTH}

The compressive strength values of the standard blocks and blocks from the five different factories are presented in Table 2. The relationship between the average compressive strength of the blocks from the five factories and blocks produced with the standard mix ratio of (1:6) and days of curing is presented in Table 2.

TABLE 2: Compressive Strength Value of Blocks Produced with The Standard Mix and the Five Block

Factories.

\begin{tabular}{|l|l|l|l|l|}
\hline $\begin{array}{l}\text { BLOCK } \\
\text { FACTOR } \\
\text { Y }\end{array}$ & DAYS & COMPRESSIVE STRENGTH VALUE $\left(\mathrm{N} / \mathrm{mm}^{2}\right)$ & $\begin{array}{l}\text { Mean } \\
\left(\mathrm{N} / \mathrm{mm}^{2}\right)\end{array}$ & $\begin{array}{l}\text { Standard } \\
\text { Deviation. } \\
(\sigma)\end{array}$ \\
\hline \multirow{4}{*}{$\mathrm{A}$} & 7 & $0.42,0.35,0.37,0.42,0.40,0.37,0.35,0.40,0.42,0.42$ & 0.39 & 0.030 \\
\cline { 2 - 6 } & 14 & $0.47,0.44,0.44,0.49,0.470 .49,0.47,0.54,0.49,0.51$ & 0.48 & 0.030 \\
\cline { 2 - 6 } & 28 & $0.63,0.65,0.67,0.63,0.70,0.61,0.65,0.67,0.63,0.65$ & 0.65 & 0.026 \\
\hline \multirow{3}{*}{$\mathrm{B}$} & 7 & $0.40,0.45,0.38,0.36,0.38,0.34,0.27,0.36,0.38,0.40$ & 0.37 & 0.047 \\
\cline { 2 - 6 } & 14 & $0.45,0.43,0.47,0.43,0.45,0.45,0.43,0.47,0.45,0.47$ & 0.45 & 0.020 \\
\cline { 2 - 6 } & 28 & $0.54,0.58,0.56,0.54,0.52,0.56,0.61,0.56,0.54,0.56$ & 0.56 & 0.025 \\
\hline C & 7 & $0.30,0.26,0.26,0.28,0.24,0.28,0.26,0.30,0.26,0.28$ & 0.27 & 0.020 \\
\cline { 2 - 6 } & 14 & $0.34,0.32,0.36,0.32,0.36,0.34,0.32,0.36,0.34,0.36$ & 0.34 & 0.018 \\
\cline { 2 - 6 } & 28 & $0.65,0.54,0.58,0.56,0.56,0.58,0.54,0.54,0.56,0.56$ & 0.56 & 0.015 \\
\hline \multirow{5}{*}{$\mathrm{D}$} & 7 & $0.56,0.63,0.61,0.58,0.61,0.63,0.61,0.67,0.58,0.63$ & 0.61 & 0.032 \\
\cline { 2 - 6 } & 14 & $0.74,0.74,0.72,0.70,0.76,0.72,0.75,0.74,0.72,0.72$ & 0.73 & 0.018 \\
\cline { 2 - 6 } & 28 & $0.96,1.01,0.99,0.96,1.01,0.99,0.96,0.94,1.01,1.01$ & 0.98 & 0.027 \\
\hline \multirow{3}{*}{$\mathrm{E}$} & 7 & $0.60,0.62,0.56,0.58,0.60,0.62,0.64,0.56,0.60,0.58$ & 0.60 & 0.026 \\
\cline { 2 - 6 } & 14 & $0.71,0.73,0.68,0.73,0.75,0.71,0.68,0.73,0.71,0.73$ & 0.72 & 0.023 \\
\cline { 2 - 6 } & 28 & $0.95,0.93,0.91,0.93,0.98,0.95,0.93,0.95,0.98,0.91$ & 0.94 & 0.025 \\
\hline \multirow{3}{*}{$\mathrm{SM}$} & 7 & $1.66,1.70,1.66,1.79,1.70,1.68,1.66,1.79,1.68,1.66$ & 1.70 & 0.051 \\
\cline { 2 - 6 } & 14 & $1.97,2.02,2.06,2.00,2.02,1.97,1.97,2.02,2.00,2.02$ & 2.01 & 0.029 \\
\cline { 2 - 6 } & 28 & $2.92,2.99,2.92,3.04,2.99,3.04,2.92,2.99,2.97,3.04$ & 2.98 & 0.049 \\
\hline
\end{tabular}

$\mathrm{SM}=$ Standard Mix Ratio of (1:6), M= Mean Value, $\sigma=$ Standard Deviation. 
The average compressive strength values of blocks from the five block factories increased with days of curing and varies from one block factory to another, 28 day average compressive strength value of $0.65,0.56,0.56$, 0.98 and $0.94 \mathrm{~N} / \mathrm{mm}^{2}$ was obtained for blocks produced from block industry $A, B, C, D$ and $E$ respectively. The 28 day compressive strength value of blocks produced with the standard mix of $1: 6$ was $2.98 \mathrm{~N} / \mathrm{mm}^{2}$. Values obtained from the five block moulding industries were lower than the British Standard value of $3.5 \mathrm{~N} / \mathrm{mm}^{2}$ and NIS $87(2000)$ value of $2.5 \mathrm{~N} / \mathrm{mm}^{2}$. However blocks produced with the standard mix did not satisfy the British standard value, but satisfied the Nigerian Industrial standard. Low compressive strength associated with blocks obtained from the five commercial block moulding industries, can be attributed to mix proportions used which is far above the standard mix ratio of (1:6) ratio specified, the water cement ratio values being greater than the upper limit of 0.45 , has effect on rate of hydration of cement, and resulted in more pores being created in the blocks after the evaporation of excess moisture from the blocks, after the hydration reaction and curing of blocks. Such voids may be responsible for low strength associated with the commercially available blocks.

Standard deviation has to do with magnitude of deviation of sample mean from the properties of individual block, and a measure of uniformity and consistency of the individual block samples produced from the block moulding factories. This will have to do with production skills and level of vibration and level of curing adopted at the different block factories. The compressive strength of standard blocks tested at 28 days have the highest standard deviation value of 0.049 , while the least value of 0.018 was obtained with 14 day compressive strength of blocks from block moulding factory $D$.

\section{Water Absorption}

The water absorption test results performed on blocks produced using the standard mix and those obtained from the five block moulding factories, is presented in Table 2.

TABLE 2: WATER ABSOPRTION TEST RESULT.

\begin{tabular}{|l|l|l|l|}
\hline $\begin{array}{l}\text { BLOCK } \\
\text { INDUSTRY }\end{array}$ & $\begin{array}{l}\text { WATER ABSOPRTION } \\
(\%)\end{array}$ & $\begin{array}{l}\text { MEAN } \\
\text { WATER } \\
\text { ABSOPRTION } \\
(\%)\end{array}$ & $\begin{array}{l}\text { STANDARD } \\
\text { DEVIATION } \\
(\sigma)\end{array}$ \\
\hline A & $8.5,8.6,8.7,8.5,8.9$ & 8.6 & 0.17 \\
\hline B & $9.2,9.1,9.3,9.2,8.9$ & 9.4 & 0.15 \\
\hline C & $9.3,9.2,9.1,9.9,9.8$ & 9.5 & 0.37 \\
\hline D & $8.1,8.4,7.6,7.9,8.3$ & 8.1 & 0.32 \\
\hline E & $8.0,7.9,7.7,7.7,7.9$ & 7.8 & 0.13 \\
\hline SM & $5.0,5.0,5.2,5.2,5.2$ & 5.1 & 0.11 \\
\hline
\end{tabular}

The average water absorption values of blocks varies from one block factory to another, water absorption values of $8.6 \%, 9.4 \% 9.5 \%$ $8.1 \%$ and $7.8 \%$ was obtained for blocks produced from block industry $\mathrm{A}, \mathrm{B}, \mathrm{C}, \mathrm{D}$, and $\mathrm{E}$ respectively. The water absorption value of standard blocks tested at 28 days have the lowest standard deviation value of 0.012 , while the maximum value of 0.028 was obtained with 28 day water absorption value of blocks from block moulding factory $A$. The water absorption value of blocks produced with the standard mix of $1: 6$ was $5.1 \%$. Values obtained from the five block moulding factories were higher than the maximum water absorption value of $7 \%$ specified for blocks by BS 2028 (1970).

Based on the results of compressive strength test and the water absorption test, commercially available sandcrete blocks produced with only sand sample are not suitable for use as side drain walling materials, and one of the factor responsible for the collapse of side drain walls observed in Abuja Municipal area.

The compressive strength values of the blocks are below values of $3.5 \mathrm{~N} / \mathrm{mm}^{2}$ and 2.5 $\mathrm{N} / \mathrm{mm}^{2}$, specified by the British Standard and the Nigerian Industrial Standard. Blocks produced with the standard mix of 1: 6 by volume satisfied 
the Nigerian Industrial Standard, but failed to satisfy the minimum compressive strength value of $3.5 \mathrm{~N} / \mathrm{mm}^{2}$ specified by the British Standard. Since drainage walls are very vital components of side drain, blocks which satisfy the British standard values of $3.5 \mathrm{~N} / \mathrm{mm}^{2}$ are suggested for use in side drain walling materials, as the side drain wall close to the shoulder of the highway or street might be subjected to wheel load.

\section{CONCLUSIONS}

The following conclusions can be drawn from the study on the suitability of commercially available sandcrete blocks produced in Abuja Municipal area using river sand as fine aggregate for use as side drain walling material.

I. Personal observations at the five different block making factories selected for the study shows that the mix ratio adopted varies from one factory to another, and in the range of $(1 ; 10)$ to (1:13) by volume. The water to cement ratio also varies from one block moulding factories to another and lies between 0.48 and 0.52 . Batching was done by volume in all the factories. The mode of curing in all the factories was by spraying/sprinkling water on the blocks twice daily for twenty eight days.

II. The 28 day compressive strength of commercially available sandcrete blocks obtained from five block moulding factories in Abuja Municipal did not satisfy the British Standard values of 3.5 $\mathrm{N} / \mathrm{mm}^{2}$ and NIS 87 (2000) value of 2.5 $\mathrm{N} / \mathrm{mm} 2$. Blocks produced with the standard mix satisfied the NIS requirement but fell short of the British requirement, and since the side drain walls are likely to be subjected to wheel load, the use of a richer mix that will satisfy the British standard values of 3.5 $\mathrm{N} / \mathrm{mm}^{2}$ is suggested for the production of blocks intended for use as side drain walling materials.

III. The water absorption values of commercially available sandcrete blocks obtained from five block moulding factories in Abuja municipal were higher than the maximum value of $7 \%$. Blocks produced with the standard mix water absorption value of $5.1 \%$ satisfied the maximum water absorption value of $7 \%$.

\section{RECOMMENDATIONS}

The quality of sandcrete blocks produced by the five factories which was sampled from the different block moulding factories did not comply with either the British or the Nigerian industrial standards, and fell short of the British standard, the use of a richer mix that will satisfy the British standard compressive strength requirement of $3.5 \mathrm{~N} / \mathrm{mm}^{2}$ at 28 days requirement is recommended or use by all block moulding factories for blocks intended for use as side drain walling materials.

\section{REFERENCES}

Abdullahi, M., 2005. Compressive strength of sandcrete blocks in Bosso and Shiroro Area of Minna, Nigeria. Assumption University Journal of Technlogy. 9, (2): 126-132.

Abgede, O. I and Joel, M., 2004. Suitability of quarry dust as partial replacement for sand in hollow block production. Nigerian Journal of Engineering Research Development. 3, (4): 33-37.

Banuso, O. R and Ejeh, S. P., 2008. Assessment of quality of sandcrete blocks in Kaduna state Nigeria. Journal of Construction. 2, (1): 11-14.

Boeck, L., Chauduri, K. P. R and Aggarwal, H. R., 2000. Sandcrete blocks for buildings: A detailed study on mix compositions, strengths and their costs. The Nigerian Engineer. 38, (1): 24-33.

British Standards (BS) 882., 1992. Aggregate for natural sources for concrete. British Standard Institute, London.

British Standards (BS) 2028., 1970. Precast concrete blocks. British Standard Institute, London.

British Standards (BS) 3921., 1965. Bricks and Blocks of earth caly or shale. British Standard Institute, London.

British Standards (BS)., 6073. 1981. Precast concrete masonry units part I: specification for precast concrete masonry Units; part II: methods for 
specifying precast Masonry units. British Standard Institute, London.

Elinwa, A. U and Chido-Amajunyi, G. U., 1991. Quarry dust as fines and the compatibility of caustic-type admixture with Ashaka cement. Nigerian Society of Engineers Technical Transaction. 28, (3):15-19.

Hall, C., 1989. Water sorptivity of mortaars and concretes. Magazine of Concrete Research. 41, (147) : 51-61.

Khannah, S. K and Justo, C. E. G., 2001. Highway engineering ( ${ }^{\text {th }}$ edition). Nem Chand and Bros, Roorkee, India.

Neville, M., 1995. Properties of concrete $\left(4^{\text {th }}\right.$ and Final edition). Addison Wesley Longman Limited, England.

Nigerian Industrial Standard (NIS)., 87. 2000. Standard for sandcrete bricks, ICS, 91. 10.20, NIS; Abuja, Nigeria.

Oyekan, L. G and Kamiyo, M. O., 2011. A study on the engineering properties of sandcrete blocks produced with rice husk ash blended cement. Journal of Engineering and Technology Research. 3, (3): 88-98.
Sadiku, A. B and Aguwa, J. I., 2013. Study of sandcrete block mixes with partial replacement of sand with quarry dust. Nigerian Society of Engineers Technical Transactions. 47, (3): 40-45.

Seeley, I. H., 1993. Building technology $\left(4^{\text {th }}\right.$ edition). Macmillan Press Itd, London.

Sharma, K. S., 2012. Principles, practice and design of highway engineering including Airport pavements ( $2^{\text {nd }}$ edition). S. Chand and company Itd. New Delhi, India.

Vallenger, A., 1971. Construction industry handbook. Medical and Technical Publishers, Aylesbury, England. 